\title{
Current St. Gallen Recommendations on Primary Therapy of Early Breast Cancer*
}

\author{
Monika Persing Regina Große \\ Klinik und Poliklinik für Gynäkologie, Martin-Luther-Universität, Halle/Saale, Germany
}

Key Words

Early breast cancer · Adjuvant therapy · St. Gallen 2007

\section{Summary}

At the 2007 10th International Conference on Primary Therapy of Early Breast Cancer in St. Gallen, the expert panel confirmed the risk classification (low, intermediate, high risk), and the definition of hormone responsiveness (endocrine responsive, endocrine non-responsive, uncertain) defined in 2005. No adjuvant therapy is only an option in the low-risk group. In the intermediate- and highrisk group, adjuvant therapy is mandatory. The choice of chemotherapy, endocrine therapy and trastuzumab therapy depends on endocrine responsiveness and risk category. Adjuvant chemotherapy should contain anthracyclines. However, in the case of node-positive tumors, taxanes should also be included. In premenopausal patients, tamoxifen is still the standard of endocrine treatment, and in some cases, ovarian function suppression should be added. In postmenopausal patients, aromatase inhibitors are an alternative to the standard tamoxifen therapy.

\section{Introduction}

This year, the 10th international meeting on 'Primary Therapy of Early Breast Cancer' since 1978 took place in St. Gallen, March 14-17. A revision of the current consensus recommen-

"Presentations at the 10th International Conference on 'Primary Therapy of Early Breast Cancer', St. Gallen, Switzerland, 2007

\author{
Schlüsselwörter \\ Frühes Mammakarzinom - Adjuvante Therapie · \\ St. Gallen 2007
}

\section{Zusammenfassung}

Auf der diesjährigen 10. Internationalen Konsensuskonferenz von St. Gallen zur primären Therapie des frühen Mammakarzinoms wurde die 2005 erarbeitete Definition der Hormonsensibilität und die Klassifikation in 3 Risikogruppen (low risk, intermediate risk, high risk) bestätigt. Der Verzicht auf eine adjuvante Therapie ist nur in der Low-Risk-Gruppe eine mögliche Option, in allen anderen Riskogruppen wird eine adjuvante Therapie empfohlen. Die Indikationen für eine Chemotherapie, endokrine Therapie und eine Trastuzumab-Therapie sind unverändert abhängig vom hormonalen Ansprechen und der Risikogruppe. Die adjuvante Chemotherapie sollte Anthrazykline enthalten, bei einem positiven Lymphknotenstatus sollten darüber hinaus Taxane zum Einsatz kommen. In der endokrinen Therapie sind bei prämenopausalen Frauen Tamoxifen und/oder eine ovarielle Suppression eine Option. Bei den postmenopausalen Patientinnen haben sich neben dem bisherigen Standard Tamoxifen die Aromatasehemmer etabliert.

dations was carried out for the primary therapy of early breast cancer. The chairmen were William Wood, USA, and Aron Goldhirsch, Switzerland/Italy. The aim of the St. Gallen consensus conferences is the establishment of evidence-based recommendations for adequate adjuvant treatment of early breast cancer. At the opening ceremony, A. Goldhirsch emphasized that the St. Gallen consensus recommendations shall not have guideline character but represent a decision support for the optimal therapy for the individual patient.

\begin{tabular}{ll}
\hline KARGER & @ 2007 S. Karger GmbH, Freiburg \\
Fax +497614520714 & Accessible online at: \\
$\begin{array}{l}\text { E-mail Information@Karger.de } \\
\text { www.karger.com }\end{array}$ & www.karger.com/brc \\
&
\end{tabular}


Table 1. Risik classification St. Gallen 2005/2007

\begin{tabular}{|c|c|c|}
\hline Low risk & Intermediate risk & High risk \\
\hline $\begin{array}{l}\text { pN0 and all of the following criteria: } \\
\text { size of tumor max. } 2 \mathrm{~cm} \\
\text { G1 } \\
\text { no vessel invasion } \\
\text { ER-/PR-positive } \\
\text { HER2-negative } \\
\text { age } \geq 35 \text { years }\end{array}$ & $\begin{array}{l}\text { pN0 and at least } 1 \text { further criterion: } \\
\text { size of tumor }>2 \mathrm{~cm} \\
\text { G2 / G3 } \\
\text { vessel invasion present } \\
\text { HER2 overexpression } \\
\text { age }<35 \text { years } \\
\text { or } \mathrm{pN}+(\mathrm{N} 1-3) \text { and HER2-negative }\end{array}$ & $\begin{array}{l}\mathrm{pN}+(\mathrm{N} 1-3) \text { and HER2 overexpression } \\
\text { or } \mathrm{pN}+(\mathrm{N} \geq 4)\end{array}$ \\
\hline
\end{tabular}

Table 2. Therapy recommendations, St. Gallen Consensus 2005/2007

\begin{tabular}{|c|c|c|}
\hline Low risk & Intermediate risk & High risk \\
\hline $\begin{array}{l}\text { endocrine therapy } \\
\text { or no therapy }\end{array}$ & $\begin{array}{l}\text { endocrine responsive } \\
\text { endocrine therapy or } \\
\text { chemotherapy then endocrine therapy } \\
\text { trastuzumab where appropriate } \\
\text { uncertain endocrine responsiveness } \\
\text { chemotherapy then endocrine therapy } \\
\text { trastuzumab where appropriate } \\
\text { endocrine non-responsive } \\
\text { chemotherapy } \\
\text { trastuzumab where appropriate }\end{array}$ & $\begin{array}{l}\text { endocrine responsive } \\
\text { chemotherapy then endocrine therapy } \\
\text { trastuzumab where appropriate } \\
\text { endocrine non-responsive } \\
\text { chemotherapy } \\
\text { trastuzumab where appropriate }\end{array}$ \\
\hline
\end{tabular}

Like in the past decade, the consensus meeting took place on the last day of the conference. The expert panel now contains 39 members from 16 different countries. The upcoming questions were tuned in the TED (televoting) method. However, due to the variety of questions (150), there was not enough time for discussion, particularly at the end.

\section{Risk Classification and Recommendations of Therapy}

At the beginning of the meeting, all members of the expert panel confirmed the risk classification established in 2005 [1], which includes the basic differentiation between endocrine responsive tumors (at least 10\% immunohistochemically positive for estrogen receptor (ER) or progesterone receptor $(\mathrm{PR})$ ), endocrine non-responsive tumors ( $0 \%$ positive cells), and tumors with uncertain endocrine responsiveness (1-9\% ER- or PR-positive cells). Patients with endocrine responsive tumors benefit from endocrine therapy with regard to improvement of overall and relapse-free survival. In patients with endocrine non-responsive tumors, endocrine therapy is of no advantage. Patients with tumors of uncertain endocrine responsiveness may or may not benefit from adjuvant endocrine treatment.

The risk classification given in 2005, differentiating between low risk, intermediate risk and high risk, remains unchanged (table 1). Assignment to a certain risk group is based on nodal status, tumor size, grade of differentiation, endocrine responsiveness, vessel invasion, and age of the patient. Endocrine therapy or even no adjuvant therapy is considered to be adequate in the low risk group only. Patients at intermediate risk of relapse are recommended to undergo endocrine therapy if the tumor is endocrine responsive. In these patients, adjuvant chemotherapy followed by endocrine therapy is also a possibility. The recommendation for patients with tumors of uncertain endocrine responsiveness includes chemotherapy followed by endocrine treatment. In endocrine non-responsive tumors, only adjuvant chemotherapy is recommended. Patients at high risk of relapse are recommended to receive adjuvant chemotherapy. In endocrine responsive tumors and tumors of uncertain endocrine responsiveness, endocrine therapy after completion of chemotherapy is recommended.

For adjuvant therapy with trastuzumab, no data were available in 2005. Due to new study results, an update was given in 2006 by the St. Gallen committee [2-5]. In the case of HER2 overexpression, adjuvant treatment with trastuzumab is recommended for all risk groups (table 2).

\section{Endocrine Therapy in Postmenopausal Patients}

In the last few years, several positive studies concerning aromatase inhibitors have been carried out [6-9]. The long-standing previous standard of a 5-year endocrine therapy with tamoxifen in endocrine responsive tumors was therefore critically analyzed. However, $75 \%$ of the members of the expert panel still regard a 5-year therapy with tamoxifen as an option. In contrast, the ASCO recommendations support the in- 
tegration of aromatase inhibitors in postmenopausal patients with endocrine responsive tumors [10]. $84 \%$ of the panel would therefore prefer the use of an aromatase inhibitor in patients with node-positive tumors. Tamoxifen is thought to be adequate especially in node-negative patients (49\%) with a strong ER and PR receptor expression (54\%). Approximately $90 \%$ of the panel members voted for a switch from tamoxifen to an aromatase inhibitor after 2-3 years. On the other hand, only $19 \%$ of the panel recommend a general upfront therapy with an aromatase inhibitor for all patients. However, in highrisk patients (61\%), patients with HER2-positive tumors (63\%) and patients treated with a selective serotonin reuptake inhibitor $(52 \%)$, the majority voted for the primary use of aromatase inhibitors.

Almost $60 \%$ of the panel members approved an extended endocrine therapy with an aromatase inhibitor after 5 years of adjuvant treatment with tamoxifen. Patients with node-positive tumors $(92 \%)$ and patients with HER2-positive tumors should receive extended endocrine therapy (74\% agreement). However, only $15 \%$ of the panel were in favor of a general extended endocrine therapy for all patients. In patients with HER2-negative tumors, an extended therapy is indicated according to $40 \%$ of the panelists. Only $25 \%$ voted for endocrine treatment to last 5 years in total. On the other hand, $85 \%$ prefer a $5-10$ year duration.

Concerning the determination of ovarian function in patients who are clinically postmenopausal but less than 55 years old, opinions differed among the panelists. $50 \%$ opted for hormone levels to be checked before or shortly after (6-12 weeks) the beginning of therapy with an aromatase inhibitor. The other $50 \%$ would forego these tests. However, there was unity concerning the question of physical activity for the prophylaxis of osteoporosis triggered by aromatase inhibitors (100\% agreement). Moreover, 61\% voted for preventative medication with calcium and vitamin $\mathrm{D}$. The general use of bisphosphonates was declined (only 3\% support). In cases of established osteoporosis, $88 \%$ recommend the use of oral bisphosphonates. $88 \%$ of the panel consistently voted for measuring the bone density prior to therapy with aromatase inhibitors.

\section{Endocrine Therapy in Premenopausal Patients}

Tamoxifen is still the standard in premenopausal women with endocrine responsive tumors. In these patients, $93 \%$ of the panel regarded a single therapy with tamoxifen as an option. $84 \%$ believe additional ovarian function suppression to be another possibility. Sole ovarian function suppression is not adequate (only $23 \%$ consent). It is only a possibility in patients who are planning a pregnancy after treatment for early breast cancer. $76 \%$ believe ovarian function suppression to be suitable for gonad protection during chemotherapy. In premenopausal patients, $94 \%$ of the panelists decline the combi- nation of an aromatase inhibitor with ovarian function suppression. This is only an option if there are contraindications for tamoxifen (68\%). Moreover, this kind of adjuvant therapy should be the subject of clinical trials ( $58 \%$ consent).

$100 \%$ of the expert panel believe ovarian function suppression by LHRH analogues to be the gold standard. $76 \%$ also regarded ovariectomy as a therapy option. Only $19 \%$ voted in favor of radiomenolysis for ovarian function suppression.

$79 \%$ of the panelists believe that the duration of medical ovarian function suppression should be individually adapted to the risk of the patient. $71 \%$ voted for a 2-year duration of ovarian function suppression for all patients. $66 \%$ believe 5 years of therapy to be appropriate in high-risk patients (nodal-positive illness, HER2 overexpression). If there is an indication for a combination of chemotherapy and ovarian function suppression, chemotherapy should be administered first followed by ovarian function suppression ( $82 \%$ consent). Simultaneous therapy is only an option in patients with incomplete family planning (86\% consent).

\section{Chemotherapy}

\section{Endocrine Non-Responsive Tumors}

According to general therapy recommendations, chemotherapy can only be omitted in patients at low risk of recurrence. In all other patients, chemotherapy should be considered. All patients with high-risk tumors are recommended to receive adjuvant chemotherapy.

There was diversity of opinion concerning the importance of HER2 status when choosing the type of chemotherapy. $40 \%$ approved a distinction, which was declined by $32 \%$ of the panelists. $22 \%$ abstained from their vote. There was more homogeneity concerning the application of anthracyclines in patients with HER2 overexpression (85\% consent). Despite the update of the BCIRG 006 study [5] which points out the cardiotoxicity risk of a therapy with anthracyclines and trastuzumab, anthracycline-containing regimens have affirmed their status even in HER2-positive tumors. Patients with triple-negative breast cancer (ER-/PR-/HER2-negative) are recommended to undergo chemotherapy containing alkylating substances ( $82 \%$ content). However, only $18 \%$ voted in favor of the use of platinum derivatives in this patient group. $59 \%$ approved a consideration of the nodal status when choosing a particular chemotherapy. Anthracyclines kept their value: $72 \%$ of the panelist believe all patients benefit from anthracycline-containing chemotherapy. The general use of taxanes was not supported by the majority of the panel $(40 \%$ consent).

The regimes ' 4 cycles of AC (cyclophosphamide, doxorubicin)' or ' 6 cycles of CMF (cyclophosphamide, methotrexate, 5-fluorouracil)' which used to be frequently used did not get the majority of votes ( $44 \%$ and $23 \%$ consent, respectively). $64 \%$ of the expert panel prefer a duration of chemotherapy for $6-8$ 
cycles. The favorite types of chemotherapy were AC followed by a taxan (73\% consent), CAF (cyclophosphamide, doxorubicin, fluorouracil) or CEF (cyclophosphamide, epirubicin, fluorouracil) (63\% consent), FEC or FAC (61\% consent). A high-dose chemotherapy with stem cell support was declined almost unanimously. The panel could not agree on a standard chemotherapy for all patients.

In patients with endocrine non-responsive and HER2-positive tumors, $50 \%$ of the panelists prefer the use of anthracyclines and taxanes. There was disagreement regarding the placement in the adjuvant treatment of by trastuzumab: $38 \%$ approved a sequential use, $41 \%$ voted for simultaneous administration, $22 \%$ abstained. $51 \%$ approved the use of carboplatin/docetaxel in HER2-positive breast cancer.

\section{Tumors with Uncertain Endocrine Responsiveness}

When choosing a chemotherapy for patients with tumors of uncertain endocrine responsiveness, several options are available: 4 cycles of AC ( $68 \%$ consent), taxane-containing regimes (49\% consent), CMF (53\% consent), FEC (57\% consent), CEF/CAF (53\% consent) or TC (carboplatin, paclitaxel) (50\% consent). Endocrine therapy should be given after the completion of adjuvant chemotherapy. All patients with (uncertain) endocrine responsive node-positive breast cancer are recommended adjuvant chemotherapy. Patients with a negative nodal status who nevertheless belong to the high-risk group should also receive chemotherapy ( $88 \%$ consent).

\section{Neoadjuvant Chemotherapy}

$42 \%$ of the expert panel approved neoadjuvant therapy in patients with endocrine non-responsive tumors. Approximately one third of the panelists believed preoperative testing of the sensitivity of the tumor to the planned therapy to be important. Only $31 \%$ voted for the use of taxanes in the neoadjuvant setting. In cases of HER 2 overexpression, $82 \%$ recommended trastuzumab therapy. Additional endocrine therapy should be given after completion of neoadjuvant chemotherapy. In patients with endocrine responsive tumors, $23 \%$ of the panelists preferred neoadjuvant chemotherapy, 50\% endocrine therapy, and $27 \%$ voted for both.

\section{Indications for Therapy with Trastuzumab}

In patients with HER2-positive tumors, adjuvant therapy is considered to be the standard ( $92 \%$ consent). Therefore, in node-negative and small $(1-2 \mathrm{~cm})$ carcinomas and in patients with endocrine responsive tumors, only $58 \%$ agreed to adjuvant therapy with trastuzumab. The panel almost agreed on the duration of trastuzumab therapy: $92 \%$ voted for a 1 -year use of the antibody. The determination of the HER2 status does not require fluorescence in situ hybridization (16\% consent). Trastuzumab is contraindicated in cases of limited left ventricular ejection fraction of $<50 \%$ ( $73 \%$ consent).

\section{References}

1 Goldhirsch A, Glick JH, Gelber RD, et al.: Meeting highlights: international expert consensus on the primary therapy of early breast cancer Ann Oncol 2005;16:1569-1583.

${ }_{2}$ Goldhirsch A, Coates AS, Gelber RD, et al.: First select the target: better choice of adjuvant treatments for breast cancer patients. Ann Oncol 2006; 17:1772-1776.

3 Piccart-Gebhardt M, Procter M, Leyland-Jones B, et al.: Randomized trial of trastuzumab following adjuvant chemotherapy in women with HER2 positive breast cancer. N Engl J Med 2005;353: 1659-1672.

4 Romind EH, Perez EA, Bryant J, Suman VJ, Geyer CE Jr, Davidson NE, et al.: Trastuzumab plus adjuvant chemotherapy for operable HER2-positive breast cancer. N Engl J Med 2005;353:1673-1684.
5 Slamon DE, Eiermann W, Robert N, Pienkowski T, Martin M, Pawlicki M, et al.: BCIRG 006: 2nd interim analysis phase III randomized trial comparing doxorubicin and cyclophosphamide followed by docetaxel $(\mathrm{AC} / \mathrm{T})$ with doxorubicin and cyclophosphamide followed by docetaxel and trastuzumab $(\mathrm{AC} / \mathrm{TH})$ with docetaxel, carboplatin and trastuzumab (TCH) in Her2neu positive early breast cancer patients. 29th Annual SABCS 2006; abstr 52

6 Jakesz R, Jonat W, Gnant M, Mittlboeck M, Greil $\mathrm{R}$, Tausch C, et al.: Switching of postmenopausal women with endocrine responsive early breast cancer to anastrozole after 2 years' adjuvant tamoxifen: combined results of the ABCSG trial 8 and ARNO 95 trial. Lancet 2006;366:455-462.

7 Goss PE, James PD, Ingle MD, Martino M, Nicholas JR, Muss HB, et al.: A randomized trial of letrozole in postmenopausal woman after five years of tamoxifen therapy for early-stage breast cancer. N Engl J Med 2003;349:1793-1802.
8 Coombes RC, Hall E, Gibson LJ, Paridaens R, Jassem J, Delozier T, et al.: A randomized trial of exemestane after two to three years of tamoxifen therapy in postmenopausal women with priumary breast cancer. N Engl J Med 2004;350:1081-1092.

9 ATAC Trialists' Group: Results of the ATAC (Arimidex, Tamoxifen, Alone or in Combination) trial after completion of 5 years' adjuvant treatment for breast cancer. Lancet 2005;365:60-63.

10 Winer EP, Hudis C, Burstein HJ, et al.: American Society of Clinical Oncology technology assessment on the use of aromatase inhibitors as adjuvan treatment for postmenopausal women with hormone receptor-positive breast cancer. Status report 2004. Clin Oncol 2005;23:619-629. 